Encyclopedia of Polymer Science and Technology Plastics, Resins, Rubbers, Fibres. Edited by Herman F. Mark, Norman G. Gaylord and Norbert M. Bikales. Vol. 1: Abaltive Polymers to Amino-Acids. Pp. xvii +893 . (New York and London: Interscience Publishers, 1964.) 3758.

7 HIS is the first volume of a 'Britannica' of plastics, resins, rubbers, and fibres. At the price of the first volume covering only ' $A$ '- 'Am', the series is obviously for the library of the university department or the larger industrial organization specializing in polymer research and development. For these, the first volume indicates that the high price of the series will be justified by the convenience of this central source of information.

The book comprises 31 review articles occupying nearly 900 pages, excellently printed and well illustrated with photographs, tables and diagrams. The articles have extensive bibliographies with references up to 1963 . The first entries listed, many cross-references to articles in later volumes, will give an idea of the broad scope: abherents, ablative polymers, abrasion resistance, abrasives, absorbers ultra-violet, absorption, ABS polymers, accelerators and activators, accumulator, acetaldehyde polymers . . .

As anticipated from Prof. Mark's unrivalled knowledge of present-day university and industrial research on polymers, the contributors are authorities on their subject, and mainly employed by industry in the United States $-a$ fair reflexion of the research effort. The selection of the contributors from universities, Prof. Bamford and Dr. Eastwood of Liverpool and Prof. Bevington of Lancaster, indicates the international ranging for the authors.

The items vary considerably in their treatment. One can sense that the "Guide to Authors" requested a comprehensive review to take up the space the author considered merited by the subject, to contain modern theory, laboratory experiment, industrial manufacture and economics, all to be salted with the author's personal enthusiasm and point of view. I found many of the topics with which I am personally acquainted to be instructive and among the best reviews on the subject. Others have made interesting and readily comprehended reading. The isolated fact or piece of information can also roadily be extracted from the clearly set-out sections of the articles.

The editors state that the subject of polymers is ripe for encyclopaedic treatment. Whether one agrees or feels that the subject is still developing at an accelerating pace, one agrees that the time is ripe to make this brave attempt to cope with the literature. By the time the last volume is published, there will probably be a demand for a second edition.

W. F. WATSON

\section{Treatise on Analytical Chemistry}

Edited by I. M. Kolthoff and Philip J. Elving, with the assistance of Ernest B. Sandell. Part 2: Analytical Chemistry of the Elements, Vol. 6. Pp. xxii +627. (New York and London: Interscience Publishers, a Division of John Wiley and Sons, 1964.) 173s.

7 HIs is another valuable edition in the series of 1 Treatise on Analytical Chemistry. Like the previous volumes the book has been written by experts in the various fields; it is well indexed and clearly laid out. The binding and finish are up to the high standard of its predecessors and the text is almost completely free from typographical errors.

The volume is subdivided into five large chapters covering concisely, but comprehensively, the full history, properties, etc., of ten elements. Each chapter is excellently organized and clearly tabulated. They make interesting reading even to the uninitiated and are of considerable value to the specialist.

The elements covered are beryllium (60 pages, 202 references), lead (95 pages, 426 references), niobium and tantalum (212 pages, 586 references), technetium (25 pages, 63 references), and actinium, astatine, francium, polonium and protactinium (164 pages, 304 references). The section on niobium and tantalum and that on lead are worthy of special mention. Niobium is as abundant as nickel so that there is good reason to study this element. All that one would wish to know about lead is covered in the excellent chapter; its occurrence, production, physical and chemical properties, isotopic distribution, alloys formed, etc., are covered in detail together with a useful, clearly tabulated series of methods of separation and isolation of lead from other elements. Its determination by polarographic, spectrographic and photometric methods is also covered in this excellent chapter.

Literary references extend to the year of publication. The volume is packed with useful and practical information. The book is obviously a 'must' for libraries of analytical laboratories or for specialists in any of the elements covered in the book. However, its limited subject-matter and its price will probably limit its sale considerably.

\section{J. THомsоN}

\section{Thermal Physics}

By Prof. Philip M. Morse. Revised edition. Pp. xiii +455 . (New York and Amsterdam: W. A. Benjamin, Inc., 1964). 10.50 dollars.

THIS is a text-book for American students in the last year of a B.Sc. course and the first year of graduate study. It covers thermodynamics, kinetic theory and statistical mechanics, and is a revision of an earlier "lecture-note volume" prepared by Prof. Morse for his class at the Massachusetts Institute of Technology.

To cover three substantial parts of classical physics in 450 pages requires a concise exposition of fundamentals and restraint in the choice of examples. Here we have both. The applications are to such modern parts of physics as the properties of superconductors, of liquid helium, and of paramagnetic substances. These are certainly the examples that will convince a student that thermal physics is still a living subject. Similarly, the section on kinetic theory at least touches on such topics of present interest as Langevin's equation and the Fokker-Planck equation for random processes. It is naturally impossible to take this section beyond a sophisticated mean-free-path treatment, but the transition to more rigorous methods should be straightforward after a careful investigation. The final part of the book on statistical mechanics proceeds briskly from a discussion of ensembles and Liouville's theorem, through information theory to the usual topics of the perfect gas, the perfect crystal and ortho- and parahydrogen. The difficulty raised by the indistinguishability of molecules is well resolved, and quantal statisties rightly get a large share of the space. The book closes with some formidable problems.

Unfortunately a substantial number of elementary errors make it impossible to recommend the book unreservedly. For example, a discussion of the third law is illustrated by a figure (p. 73) in which entropy is proportional to temperature at absolute zero; a phase diagram of helium (p. 131) has a vapour pressure of $8 \mathrm{~mm}$ mercury at absolute zero; other diagrams (pp. 123, 129) show a solid with a non-zero coefficient of thermal expansion at absolute zero and a representation of the Gibbs free-energy which implies that the heat capacity of a liquid is negative. Chemical reactions (pp. 138-9) are discussed on the impossible premise that equilibrium can lie so far to one side that one of the reactants can "run out" before it is reached. The dimensionless ratio of the thermal conductivity to the viscosity of a gas is derived as $5 / 3$, and it is stated that this value is confirmed by experiment (p. 220). The true value is $5 / 2$ for monatomic gases (although its derivation is beyond the scope of this book) and it is this value that is confirmed by experiment. The vibrational heat capacity of polyatomic gases (p. 323) is certainly not small "below about $1,000^{\circ} \mathrm{K} "$.

The book uses M.K.s. units throughout. The table of fundamental constants has not been revised to conform to the 1960 unified scale of atomic mass based on ${ }^{12} \mathrm{C}=12$. 